\title{
La equidad de género, meta aún no alcanzada en las universidades
}

a equidad de género es una meta aún no alcanzada en las universidades. Aunque actualmente hombres que estudian educación superior, persisten las desigualdades en la cobertura que alcanzan los distintos países del mundo y al interior de éstos, así como en los ámbitos disciplinar y laboral. En ese contexto, muchas universidades han asumido la equidad de género como uno de sus principios fundamentales y han formulado e implementado políticas para alcanzarla. No obstante, el camino por andar es aún muy grande como lo muestran los artículos que se presentan en este número de revista Universidades de la UDUAL.

Con el objetivo de analizar los cambios institucionales que la agenda feminista está produciendo en la Universidad Nacional de Río Negro, Mariana Rulli expone en su artículo "(Des)igualdades de género, avances normativos y políticas de igualdad en la Universidad Nacional de Río Negro (UNRN) (Patagonia, Argentina)" los cambios que dicha institución realiza con objeto de promover la igualdad de género, mismos que estuvieron impulsados por la lucha de las mujeres que integran los claustros de la universidad. Con base en su estudio sobre participación política y cargos jerárquicos de la UNRN, se discute un Protocolo de Actuación contra las Violencias de Género, así como los ejes para la elaboración de un Plan de Igualdad en la universidad. Entre sus conclusiones vale la pena subrayar el esfuerzo de esta institución educativa por visibilizar dichas desigualdades en el interior de la universidad, por normar las relaciones de género en sus aulas y por establecer mecanismos y políticas para combatirlas. 
Por su parte María Elena Carbonell Yáñez, en su artículo "Género y educación superior. La representación de las mujeres en las facultades de Derecho de la ciudad de Quito", da luz sobre la discriminación entre los y las docentes de la universidad en algunas facultades de Derecho en esa ciudad, donde la ausencia de paridad entre profesionales hombres y mujeres evidencia que aún existen obstáculos estructurales, formales e informales que impiden que la universidad sea el espacio diverso e integrador que se plantea.

Finalmente, el artículo "Universidad y maternidad. Madres universitarias en la Universidad de Sonora" de José Raúl Rodríguez Jiménez, Brenda Judith Millanes Campa y Juan Pablo Durand Villalobos presenta una realidad muy presente en las instituciones educativas de nivel superior. A través de entrevistas, el artículo detalla las características demográficas de estudiantes universitarias que son madres solteras que se enfrentaron a un embarazo sorpresivo, y nos habla de sus vivencias como madres y estudiantes y de la importancia de los apoyos familiares para que puedan hacer frente a su situación de manera positiva.

Las realidades que abordan estos artículos nos permiten apreciar la necesidad de seguir luchado en las instituciones universitarias para enfrentar los importantes retos que enfrentan en el camino para lograr la equidad de género. 
